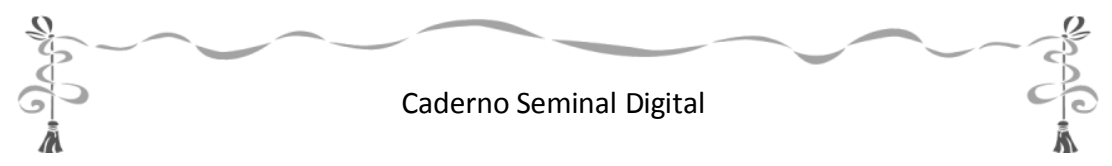

\title{
EM BUSCA DE UMA CONCEPÇÃO DE MARCADOR DISCURSIVO PARA O ENSINO DE PORTUGUÊS LÍNGUA ESTRANGEIRA (PLE)
}

FOR A NEW CONCEPTION ON DISCOURSE MARKERS IN THE TEACHING OF PORTUGUESE AS A FOREIGN LANGUAGE

Maria D’Ajuda Alomba Ribeiro

UESC

Resumo: Atualmente, a abordagem intercultural tem orientado o ensino de línguas. Essa prerrogativa propõe novas orientações no âmbito do ensino, ampliando o campo de reflexão e estudo dentro da área de aprendizagem de línguas. $O$ ensino de Português como Língua Estrangeira, (doravante PLE), por sua vez, tem sofrido vários avanços. Diante dessa notabilidade, a comunicação emergente apresenta uma reflexão sobre os resultados obtidos através da pesquisa desenvolvida na Universidade de Alcalá, cuja temática versou sobre o ensino dos Marcadores discursivos para estudantes hispanoparlantes aprendizes de português. A pesquisa teve como corpus a produção escrita desses aprendizes cujo enfoque centrou-se na análise qualitativa e quantitativa dos erros na construção do discurso. Os resultados obtidos contribuíram para a investigação do PLE na Universidade Estadual de Santa Cruz, em especial no discurso escrito dos alunos oriundos da Espanha possibilitando um olhar mais aguçado sobre as dificuldades enfrentadas por estes e as possíveis causas as que se podem atribuir ditos erros.

Palavras- chave: Língua Estrangeira - Ensino - Língua Portuguesa Marcadores discursivos.

Abstract: Nowadays the cultural approach has supported Language teaching. This prerogative brings new conceptions for teaching, expanding the reflection upon teaching languages. The teaching of Portuguese as a Foreign Language (henceforth PFL) has been impacted by some advances. The emerging communication presents some reflections on the results

Caderno Seminal Digital Ano 19, no 19, V. 19 (Jan-Jun/2013) - ISSN 1806-9142
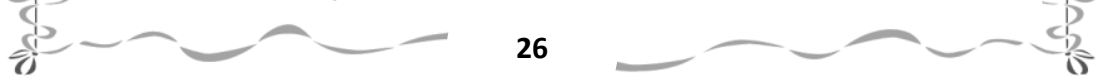
obtained through research carried out at Alcalá University - Spain, with the topics focus on teaching of Discourse markers for Spanish speakers who were PFL students. That research had as its material the written production of those learners focused in the qualitative and quantitative analysis of the errors on discourse. The results obtained has contributed to investigation of PFL at UESC (St. Cross State University), specially written production of some of those students from some other countries, offering a more profound gaze about difficulties to be faced by them and the possible causes to some errors.

Keywords: Foreign Language - Teaching - Portuguese - Discourse markers.

\section{PRELIMINARES}

Esta investigação foi alimentada por duas vertentes: a difusão do português no âmbito hispânico e a introdução no ensino dos marcadores discursivos. A respeito do primeiro, é um dado relevante a expansão da Língua Portuguesa como Língua Estrangeira (doravante PLE), as políticas para o ensino e aprendizagem de línguas estrangeiras (LE), as quais estão em ascensão. Há vários fatores contribuindo para essa tendência, entre os quais a globalização que dentro deste processo econômico, muitos países se juntaram e formaram blocos econômicos, cujo objetivo principal é aumentar as relações comerciais entre os membros e com isso surgem os acordos político-econômicos entre os países do MERCORSUL, que têm desencadeado um interesse pelo processo de ensino tanto do idioma espanhol como do português nos países envolvidos.

Caderno Seminal Digital Ano 19, no 19, V. 19 (Jan-Jun/2013) - ISSN 1806-9142
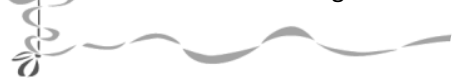

27

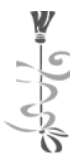


Nesse contexto, observa que o ensino de PLE tem crescido muito nos últimos anos. Diante desse cenário, uma das razões mais frequentes que estimulam o estudante estrangeiro a aprender português é a interação comunicativa entre os interlocutores, tornando emergente a necessidade de um bom manejo do discurso falado e escrito. Assim, a produção escrita exige, entre ostros aspectos, o monitoramento linguístico e uso adequado dos marcadores próprios do estilo formal, responsável pela progressão argumentativa que o falante realiza para a aprendizagem do português como língua estrangeira.

Nessa perspectiva, entre o PLE e outras línguas observa-se que o aluno, cuja língua nativa é o espanhol, na sua aproximação com o português apresenta uma série de traços comuns, mesmo sendo aluno principiante. Ao discutir a aprendizagem de língua estrangeira, partindo dos pressupostos das teorias do ensino de línguas, todo falante de espanhol a priori tem conhecimentos e habilidades comuns entre a língua de origem e a língua-alvo. Para Almeida Filho (1993), o aluno vivencia uma incômoda sensação: a de perceber uma ausência de claros definidores de aspectos da nova língua que servem para construir o entremeado sobre o que fundamenta seu processo de aprendizagem. Este último aspecto se relaciona com a dificuldade que supõe para o aluno, na sua produção escrita ao usar os marcadores. Para os aprendizes hispanoparlantes, os quais geralmente alimentam uma falsa ideia de facilidade comunicativa induzida pela

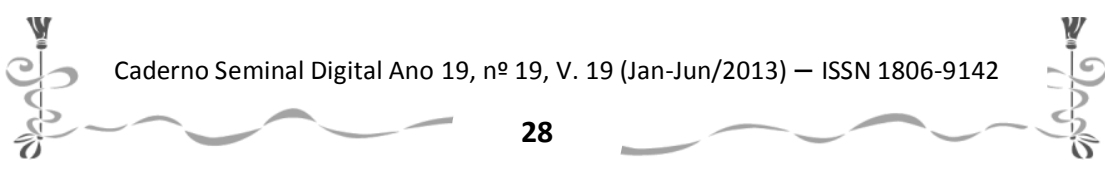


Caderno Seminal Digital

î.

風

semelhança entre a língua materna e a língua estrangeira (LM e LE). Com essa crescente demanda, tem aumentado o interesse por parte dos professores de PLE porem desenvolver instrumentos de ensino mais eficazes que conduzam a superação das dificuldades provenientes em alguns casos de semelhança entre as duas línguas ao contrastá-las.

Entre as dificuldades, temos identificado as que se referem aos marcadores argumentativos pela dificuldade do uso dos conectores em contextos profissionais, pois isso exige dos falantes maior capacidade argumentativa na defesa ou discussão dos seus argumentos.

Assim, nossa atenção voltou-se para os conectores argumentativos. Esses são aqueles MDs que estabelecem uma relação argumentativa no discurso e que conduzem ao receptor determinadas inferências e conclusões. Daí que sua manifestação seja tratada como um signo de identidade do texto argumentativo, signo de identidade, mas não privativo, pois esses conectores se dão também na narração, na exposição e na descrição, esta última muito usada, sobretudo pelos aprendizes do nível inicial. Nessa linha de pensamento, não se pode surpreender que "em sentido débil todo texto é argumentativo" (NÚÑEZ e DEL TESO 1996, p. 193)². O texto argumentativo é aquele tipo textual que aporta razões e

${ }^{2}$ Esta é a intuição pela qual descansa a Rethorical Structure Theory de Mann e Thompson.

Caderno Seminal Digital Ano 19, no 19, V. 19 (Jan-Jun/2013) - ISSN 1806-9142 
Caderno Seminal Digital

î.

argumentos com o propósito de mover ao receptor a uma determinada conclusão.

Com esta definição, podemos dizer que a argumentação, assim como qualquer outro tipo de texto, é o resultado de um processo cognitivo que precisa de conhecimento dos elementos linguísticos para constituir e relacionar argumentos que levem a umas determinadas conclusões, a favor ou contra uma determinada opinião.

Para fomentar esta investigação, analisou-se desde sua perspectiva teórica até chegar a aplicação sistemática da análise dos erros, um corpus de 150 composições livres, constituído de textos pertencentes não só às características argumentativas, mas também aos tipos narrativo e descritivo. As produções escritas foram produzidas por hispanoparlantes aprendizes de PLE, alunos do Centro de Línguas Estrangeiras da Universidade de Alcalá, entre o período de outubro de 2001 a junho de 2003. Elaboramos a classificação, descrição e análises detalhando os erros, podendo detectar que tipos de erros ou equívoco apresentam, quais são os mais problemáticos e porque se produz quando os alunos têm de usar os conectores argumentativos e contra-argumentativos na produção escrita. Para o entendimento do estudo dos erros, nos baseamos na teoria da metodologia da análise de erros.

Diante do exposto, fizemos uma reanálise dos marcadores discursivos incluindo uma proposta classificatória

Caderno Seminal Digital Ano 19, no 19, V. 19 (Jan-Jun/2013) - ISSN 1806-9142 
desde distintos enfoques teóricos da Linguística Aplicada, como a importância de analisar a aquisição linguística da língua-alvo através dos textos produzidos. A partir dessas classificações já existentes, propusemos uma adaptação que desse conta da nossa análise. Ressaltamos que a classificação que propomos é, sem dúvida, discutível, pois acreditamos ter cumprido nosso primeiro objetivo, de proporcionar uma visão um pouco mais clara do que sejam os marcadores do discurso no âmbito da Linguística Aplicada, ampliando um pouco mais os estudos neste campo.

Uma vez delimitado e caracterizado o grupo que denominamos marcadores discursivos, nosso segundo objetivo foi estabelecer a unidade mínima de análises desses conectores apresentados nas composições dos hispanoparlantes, pertencentes ao sistema da língua. Embora esta investigação tenha centrado na análise dos conectores argumentativos presentes no discurso escrito, não relegamos em ocasiões o encontro da realidade comunicativa no discurso oral, o que nos permitiu ampliar os usos e valores do conector quando aparece em diferentes contextos. Diante disso, foi possível observar se os alunos cometem erros ou se equivocam ao se apropriar de certos valores ao usar o conector na L2.

Para analisar os erros, nos apoiamos na teoria da Análise de Erros ( doravante $\mathrm{AE}$ ) com algumas contribuições da Análise Contrastiva (doravante AC). As classificações

Caderno Seminal Digital Ano 19, no 19, V. 19 (Jan-Jun/2013) - ISSN 1806-9142 
desenvolvidas neste trabalho abarcam todas as categorias da língua, entretanto, no que se refere ao discurso, são bastante superficiais. Ante a inexistência (G. VAZQUEZ, 1991; SANTOS GARGALLO, 1993) ou inadequação (S. FERNÁNDEZ, 1997) dos critérios estabelecidos para a análise de erros discursivos, reelaboramos uma proposta de critérios desde uma perspectiva morfossintática e semântica, a partir da já existente, com o propósito de que nos proporcione uma classificação dos erros no uso dos conectores argumentativos e contra-argumentativos na produção escrita. Tal proposta, condicionada pelas unidades presentes no corpus, contemplou quatro tipos de erros: adição, omissão e eleição de modo e tempo verbal.

A interface entre a metodologia da $A E$, os conceitos e funções dos conectores tomados da Teoria de Argumentação mais as contribuições da pragmática nos levaram a entender claramente não só a finalidade dos conectores presentes no discurso, mas também a intenção do emissor. Inclusive, quando esta não estava explícita, devido ao uso inadequado dos marcadores, houve uma maior confiabilidade em nossa análise e uma maior segurança em nossas explicações.

Os dados proporcionados pela produção linguística dos hispanoparlantes aprendizes de PLE, a partir dos paradigmas quantitativo e qualitativo, ratificaram a hipótese de interferência da língua materna como causa da maioria dos erros no uso dos elementos linguísticos em estudo.

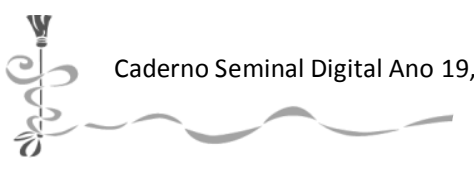

32 
No decorrer do estudo, quando resenhamos as teorias e os métodos no ensino de línguas estrangeiras, evidenciamos o papel da LM no processo de aprendizagem da L2. Embora não haja ainda um acordo sobre que tipo de influencia exerce exatamente a LM sobre o processo de aprendizagem da L2, se admite a existência de erros provocados pela interferência da LM na L2. Assim, na aprendizagem de uma língua que se assemelha a L1 dos aprendizes, como acontece com o espanhol e o português, a língua materna serve de base e facilita a aprendizagem da $L 2$, sobretudo nos níveis iniciais. Entretanto, os níveis mais avançados, os erros tendem a persistir e são difíceis de excluir, devido a interferência da L1 e, no caso dos conectores, há a progressiva complexidade dos textos que se exige ${ }^{3}$. Em ambos os níveis, a LM interfere na aprendizagem da L2, mas não da mesma forma. No primeiro caso, funciona como fator de aperfeiçoamento da competência comunicativa. De fato, nessa investigação constatamos que a maioria dos erros no uso dos conectores argumentativos, produzidos pelos alunos de PLE, são devidos à interferência de sua língua materna.

Para melhor apreciação dos resultados quantitativos e qualitativos dos erros, transcrevemos a continuação um gráfico no que apresenta os casos e estrutura específica dos

\footnotetext{
${ }^{3}$ Neste trabalho procuramos não centrar a atenção sobre os aspectos da transferência e interferência, pois ao utilizar as teorias de Análise de Erros e a metodologia de Análise Contrastiva não temos como indagação compreender os processos mentais que desencadeiam os erros direta ou indiretamente.
}

Caderno Seminal Digital Ano 19, no 19, V. 19 (Jan-Jun/2013) - ISSN 1806-9142

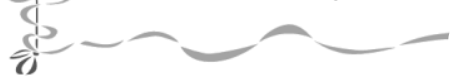


Caderno Seminal Digital

î.

erros produzidos pelos hispanoparlantes ao usar os conectores na L2.

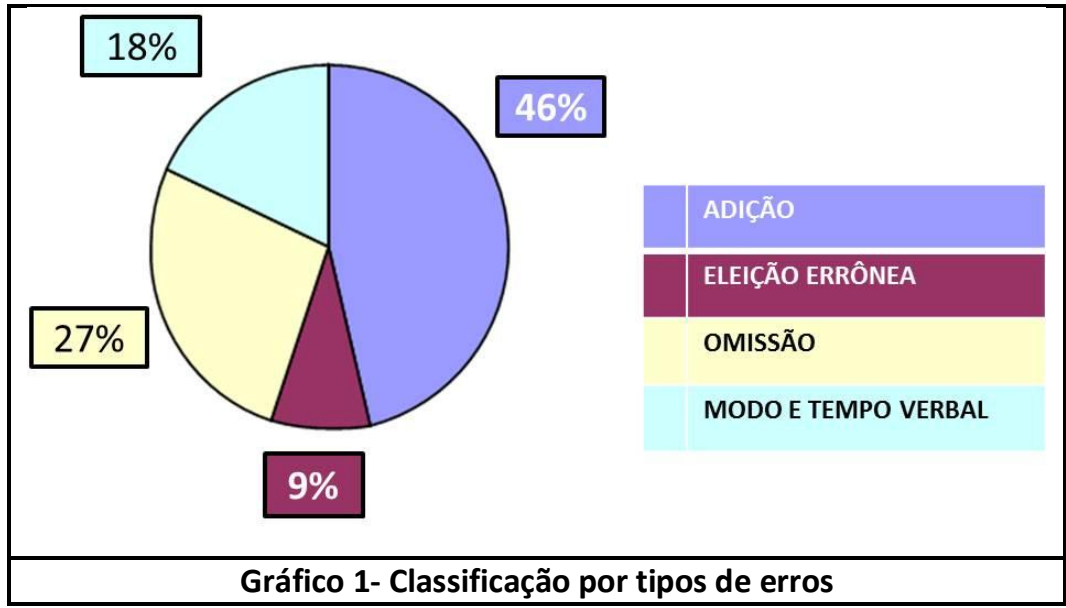

Como se pode observar, $46 \%$ dos erros se referem à adição dos conectivos seguida por $27 \%$ de erros na omissão. 0 terceiro tipo de erro mais produzido corresponde à eleição errônea de um conectivo, seguida dos erros de modo e tempo verbal que representam a menor cifra com $9 \%$.

Os dados revelam que a adição tem mais problemas para os aprendizes, seguido do uso errôneo da omissão e erros de modo e tempo verbal no uso dos conectores concessivos. Observando a porcentagem dos erros, pode-se dizer que houve um distanciamento entre os níveis elementar e intermediário, mas entre o nível intermédio e avançado

Caderno Seminal Digital Ano 19, no 19, V. 19 (Jan-Jun/2013) - ISSN 1806-9142 
Caderno Seminal Digital

î.

nota-se uma evolução positiva do que vimos uma gravidade de erros nos níveis anteriores.

Os alunos do nível elementar são os que apresentam mais problemas, sendo que os erros apresentam uma evolução negativa. Nos primeiros níveis, sua porcentagem oscila entre diferentes etapas. Esse fato não quer dizer que houve mais assimilação ao usar o marcador, ocorre o fenômeno da omissão ou o câmbio por outra palavra para prevenir possível erros, podendo ser uma interação das interferências interlingual e intralingual, além de uma intervenção da língua materna ao longo da aprendizagem no uso dos conectivos que os aprendizes optam erroneamente. A respeito da omissão, estes são mais significativos, havendo uma tendência a diminuir os erros a medida que aumenta o conhecimento dos alunos.

Em termos numéricos, esta investigação analisou 402 erros (sendo 249 erros na construção do discurso e 153 significante), que em relação ao número total de usos corretos (919) que equivale a uma média de erros de $31 \%$, número relativamente alto para o grupo de conectivo investigado. Isso quer dizer que o uso dos conectivos pelos hispanoparlantes é um problema acerca da interferência da LM. Portanto, essa categoria merece uma atenção especial no momento de realizar estratégia para o ensino dos conectivos no contexto de PLE. Não observamos os resultados só dos acertos e dos erros avaliados, mas também a porcentagem

Caderno Seminal Digital Ano 19, no 19, V. 19 (Jan-Jun/2013) - ISSN 1806-9142

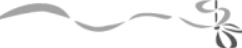


Caderno Seminal Digital

î.

relativa, já que se pode pensar que um número maior de erros implica uma dificuldade maior para os aprendizes e não ter em conta seus certos na produção. No gráfico seguinte demonstramos a análise quantitativa e a média de erros em cada nível.

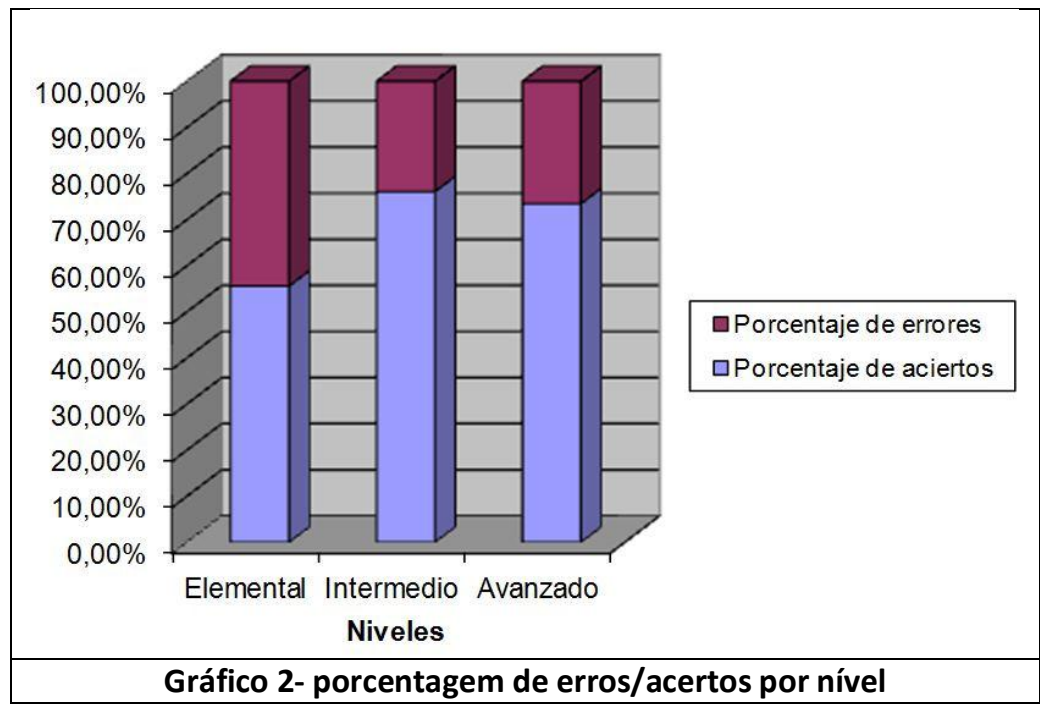

As porcentagens que mostram o gráfico são muito significativas e isso quer dizer que os erros no uso dos conectivos são persistentes em etapas sucessivas e mais elevadas, embora a porcentagem não diminua o número absoluto de erros. Sendo assim, se observa a porcentagem do nível elementar, nota se que os erros correspondem quase a metade das produções escritas pelos alunos, contudo estão nos níveis intermédio e avançado. Apenas existe diferença no

Caderno Seminal Digital Ano 19, no 19, V. 19 (Jan-Jun/2013) - ISSN 1806-9142 
processo de aprendizagem no uso dos conectivo tende a diminuir nestes dois níveis.

Enquanto ao tipo de erros, assim foi a distribuição. Os 402 erros foram distribuídos 114 de adição, 23 de eleição errônea, 66 de omissão e 46 erros de tempo e modo verbal que corresponde respectivamente a $46 \%, 9 \%, 27 \%$ e $18 \%$. Dos erros encontrados, 153 são erros no significantes, dos quais 86 casos se referem ao uso do conector adversativo, provenientes dos seguintes níveis: 39 casos estão no nível elementar, 32 no nível intermédio e 15 no nível avançado. Esses erros podem ser atribuídos à confusão que os alunos têm em relação às normas de uso dos conectores da língua meta.

Dos conectivos contra-argumentativos, o que mais apresentou problemas foi o conectivo mas. Em 32 dos casos, a forma mas foi substituída pelo advérbio mais, segundo a seguinte distribuição: 11 desses se dão no nível elementar, 15 no nível intermédio e 6 no nível avançado. Este tipo de erro do vocábulo mais se podia classificar como um caso de interferência fonética entre o advérbio português mais e o advérbio espanhol más e, no caso do corpus utilizado, os alunos se apegaram à palavra mais quando ouviram não só a professora, como também aos companheiros, deduzindo erroneamente que a forma correta para utilizar a conjunção mas, que em português fala e escreve como em espanhol, era utilizar o mais em vez do mas. Nessa linha de pensamento,

Caderno Seminal Digital Ano 19, no 19, V. 19 (Jan-Jun/2013) - ISSN 1806-9142
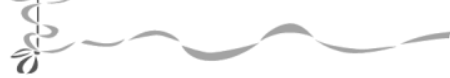
consideramos que este tipo de interferência pode afetar grau de dificuldade para o aluno de uma língua estrangeira, como também a interferência do registro oral. Com o objetivo de ensinar ao aluno a diferenciar mas de mais, podíamos recorrer a atividades auditivas. Contudo, as atividades podem realizarse de maneira solitária, para fazer ouvir aos estudantes e apresentar um texto transliterado, com rigorosa ortografia da amostra de fala que tenha escutado.

No caso concreto da língua estrangeira, o conhecimento do léxico provavelmente será parcial, já que o aluno pode dominar algumas propriedades lexicais e não dominar outras. Laufer (1989) propõe que o conhecimento de uma palavra implica o conhecimento da sua forma (fonológica, gráfica e morfológica), seu comportamento sintático, seu significado (referencial, associativo, pragmático) e suas relações com outras palavras (paradigmáticas e sintagmáticas).

Finalmente, confirmamos que os alunos se apoiam em estratégias semânticas, sintáticas, pragmáticas e estilísticas que contribuíram com o cumprimento dos objetivos da produção. Esses recursos não são utilizados de forma consciente pelos alunos e em geral são aprendidas à medida que esses alunos passam a produzir diversos tipos de composições.

Assim, observamos o uso de determinadas estratégias sistemáticas e comuns em relação a alguns alunos em

Caderno Seminal Digital Ano 19, no 19, V. 19 (Jan-Jun/2013) - ISSN 1806-9142

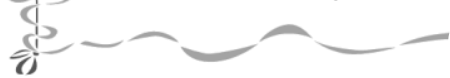


Caderno Seminal Digital

î.

pequeno número, uma vez que estas podem ser válidas para outros aprendizes de português como língua estrangeira, cuja língua materna não tenha troncos comuns ao espanhol, considerando que são estratégias universais, como: a simplificação generalização. É um processo de aproximação dos idiomas onde surgem os inumeráveis problemas de generalização da igualdade ou de facilidade comunicativa, que oculta muitas vezes a dificuldade gramatical. Com relação a esse aspecto Toríjano \& Agustin (2004) propõe que se aproveite as generalizações que o aprendiz faz para conhecer o ponto de partida e caminha muito lentamente, até a aquisição de outra língua.

A análise realizada nas composições dos alunos demonstra que tem um conhecimento linguístico suficiente para produzir textos, o qual se observa na maioria das relações explícitas dos conectores utilizados para introduzir os argumentos. Nesse trabalho, objetivamos uma situação em que os alunos deviam produzir textos livres. De acordo com os dados, observou-se que tais discentes utilizaram conhecimento de sua competência textual para produzir textos narrativos e descritivos com superestrutura para o texto argumentativo. Deste modo, comprova-se que os membros de uma cultura dada podem conhecer qual é a organização global de várias tipologias textuais da língua portuguesa.

Caderno Seminal Digital Ano 19, no 19, V. 19 (Jan-Jun/2013) - ISSN 1806-9142 
Os 21 informantes que participaram nesse trabalho constituem uma amostra representativa dos estudantes de PLE, são falantes de espanhol que estão motivados para aprender o português do Brasil. Embora os alunos não tenham estudado em um ambiente de imersão, observa-se que os resultados obtidos no que se refere ao uso dos conectores argumentativos e contra-argumentativos, apresentam coerência ao amparar os objetivos dessa investigação. 0 ensino do uso dos conectores na escrita dos alunos aprendizes de português precisa ser objeto de novas investigações pela importância que estes têm tanto na argumentação escrita, como no desenvolvimento de outras habilidades comunicativas. $O$ ensino desses conectores é relevante não só para o ensino de PLE como também para o ensino da $L M$, além dos diversos pontos de vista não só desde uma perspectiva puramente gramatical já que:

Hoy se entrecruzan en provechoso maridaje la psicolingüística, la sociolingüística, la pragmática, la semiótica, la etnografía de la comunicación, la lingüística textual y el discurso oral con su joven hija la teoría de la conversación. Se estudia detenidamente el proceso de aprendizaje, se somete a diversos asedios el concepto de competencia comunicativa, se trabaja con detalle la multiplicidad de objetivos en relación con el tipo de enseñanza, se revisan y vuelven a revisar los contenidos curriculares, se replantea lo relativo a las

Caderno Seminal Digital Ano 19, no 19, V. 19 (Jan-Jun/2013) - ISSN 1806-9142

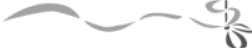




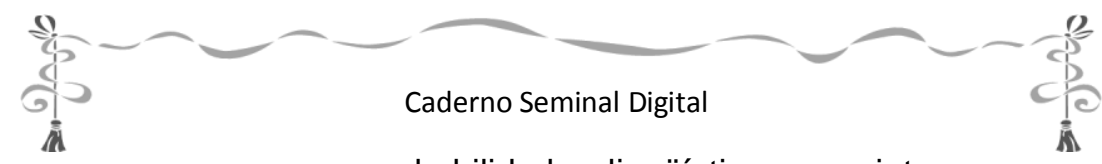

habilidades lingüísticas que interesan, se analizan nuevos procesos de evaluación y se incorpora a todas estas tareas el maravilloso mundo de la tecnología. (MORALES, 2004, p.17).

Sendo assim, esperamos que os resultados dessa investigação possam contribuir a intervenção no ensino de PLE mediante uso de metodologia e materiais mais adequados e eficazes, que tenham em conta as estratégias, as interferências e as insuficiências na formação de estudantes de línguas estrangeiras, no que concerne a sua capacidade argumentativa no uso da linguagem escrita.

Acreditamos que esse trabalho tenha alcançado os objetivos propostos. Esperamos que não seja tarde para pensar que, dedicando um pouco mais de esforço, podemos, a partir do conhecimento das causas, dos erros, refletir sobre o ensino dos conectores argumentativos e contraargumentativos na produção escrita de PLE e que esses possam promover uma progressiva aprendizagem de ditos elementos e a consequente redução dos erros nos níveis que esses deveriam estar superados. Assim, acreditamos, na possibilidade de que futuras investigações possam ir mais adiante.

Toda essa complexidade está ligada à atividade de estruturação dos enunciados pelos aprendizes. Ressaltamos o fato de que existe uma margem muito ampla de liberdade organizacional, suscetível a múltiplas pressões ligadas à

Caderno Seminal Digital Ano 19, no 19, V. 19 (Jan-Jun/2013) - ISSN 1806-9142

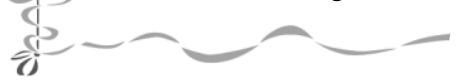

41

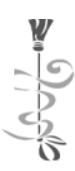


Caderno Seminal Digital

î.

necessidade e ao desejo de sucesso na interação. Entendemos, desse modo, as diferentes funções-textuais que o falante pretende demonstrar, já que a norma tradicional não responde o que questionamos, sobretudo no ensino de PLE. Para tanto, urge a necessidade de rever o uso desses elementos linguísticos sob o prisma do discurso, o que nos levará ao encontro de soluções metodológicas que possam superar não só a situação enganosa da facilidade, como também certas áreas de dificuldade no ensino-aprendizagem do português para hispanoparlantes.

\section{REFERENCIAS BIBLIOGRÁFICAS}

ALMEIDA FILHO, P. José Carlos de. Dimensões comunicativas no ensino de línguas, Campinas: Pontes, 1993.

FERNÁNDEZ LÓPEZ, S. Interlengua y Análisis de errores en el aprendizaje del español como lengua extranjera, Madrid: Edelsa, 1997.

LAUFER, B. "A factor of difficulty in vocabulary learning: deceptive transparency", Ron C. y Nation, P. (org.) Vocabulary acquisition, Montreal: Université de Montreal, 1989.

LÓPES MORALES, H. "Prologo" a J. Sánchez Lobato y I. Santos Gargallo (Org.) Vademécum para la formación del español del profesor, Madrid: SGEL.

NUNEZ, R. e DEL TESO. Semántica y pragmática del texto común. Producción y comentario de texto. Madrid: Cátedra, 1996.

SANTOS GARGALO, I. Análisis contrastivo, análisis de errores e

Caderno Seminal Digital Ano 19, no 19, V. 19 (Jan-Jun/2013) - ISSN 1806-9142 
a

\section{Caderno Seminal Digital \\ Caderno Seminal Digital}

interlengua en el marco de la lingüística contrastiva. Madrid:

Síntesis, 1993.

TORÍJANO Pérez, J. Agustín. Errores de Aprendizaje, Aprendizaje de los Errores. Madrid: Arco Libros, 2004.

VÁZQUEZ, G. Análisis de errores y aprendizaje de español/lengua extranjera, Análisis, explicación y terapia de errores transitorios y fosilizables en el proceso de aprendizaje del español como lengua extranjera en cursos universitarios para hablantes de alemán, Frankfurt am Main: Peter Lang, 1991. 